$01,05,16$

\title{
Ближний порядок в магнитомягком сплаве $\alpha$-FeAl
}

\author{
(С Н.В. Ершов ${ }^{1}$, Ю.П. Черненков ${ }^{2}$, В.А. Лукшина ${ }^{1,3}$, О.П. Смирнов ${ }^{2}$ \\ ${ }^{1}$ Институт фоизики металлов УрО РАН, \\ Екатеринбург, Россия \\ ${ }^{2}$ Петербургский институт ядерной физики, НИЦ „Курчатовский институт“, \\ Гатчина, Россия \\ ${ }^{3}$ Уральский федеральный университет, \\ Екатеринбург, Россия \\ E-mail: nershov@imp.uran.ru
}

(Поступила в Редакцию 1 февраля 2018 г.)

Атомная структура образцов сплава железо-алюминий, содержащего около 7 at.\% алюминия ( $\alpha$-область фазовой диаграммы), исследовалась методом рентгеновской дифракции. Образцы отжигались в парамагнитном $\left(T>T_{C}\right)$ и в ферромагнитном $\left(T<T_{C}\right)$ состояниях. В первом случае структурное состояние фиксировалось закалкой от температуры отжига в воду, во втором - медленным охлаждением. Дифрактограммы от монокристаллических образцов снимались на рентгеновском четырехкружном дифрактометре. Показано, что локальное упорядочение независимо от предыстории образца представляет собой сочетание кластеров B2-фазы (типа $\mathrm{CsCl}$ ), которые ранее были обнаружены в железокремнистых сплавах при содержании $\mathrm{Si}$ до $10 \%$, и малых областей с $D 0_{3}$ ближним порядком. Если первые состоят из двух $B 2$-ячеек, имеющих общую грань, то вторые - преимущественно из одной элементарной ячейки $D 0_{3}$-фазы. В пределах точности эксперимента существенной разницы структурных состояний в парамагнитной и ферромагнитной фазах не обнаружено.

Работа выполнена в рамках государственного задания ФАНО России (тема „Магнит“, № 01201463328) при частичной финансовой поддержке РФФИ в рамках научного проекта № 18-02-00391.

DOI: $10.21883 /$ FTT.2018.09.46375.028

\section{1. Введение}

Богатые железом сплавы железа и алюминия стали объектами, привлекающими значительный научный интерес с 1932 г., когда Bradley и Јау представили результаты рентгеноструктурного исследования сплавов этой системы [1]. Они показали, что в сплавах, содержащих более $\sim 19$ at.\% Al образуются упорядоченные фазы со структурами $B 2$ и $D_{3}$. В последние годы к сплавам $\mathrm{Fe}-\mathrm{Al}$ интерес вновь усилился, поскольку они проявляют важные для практического применения высокие технологические свойства [2]. Железоалюминиевые сплавы устойчивы к окислению и коррозии, имеют хорошую пластичность при комнатной температуре, относительно низкую плотность, высокое значение магнитной проницаемости, а также хорошо поглощают механическую вибрацию. С другой стороны, сплавы Fe-Al представляют интерес, поскольку в них можно изучать критическое поведение системы при фазовых переходах [3,4], например, между ферромагнитной, парамагнитной и спинстеклоподобной фазами $[5,6]$.

В $\alpha$-области фазовой диаграммы (до 20 at.\% Al) сплавы железа с алюминием обладают магнитомягкими свойствами и характеризуются важными для их практического применения особенностями, которые связаны с их структурным состоянием. К таким структурно обусловленным свойствам относятся:

1. Возможность формирования в сплавах анизотропии магнитных свойств под действием магнитного поля или механического напряжения во время отжига в ферромагнитном состоянии [7-11], - наведенная магнитная анизотропия, как эффект термомагнитной или термомеханической обработки.

2. Квадратичная концентрационная зависимость коэффициента тетрагональной магнитострикции от концентрации $\left(\lambda_{100} \sim C_{\mathrm{Al}}^{2}\right)$, аналогичная той, что наблюдается при небольших концентрациях растворенного элемента в сплавах железа с галлием, германием или бериллием, обладающих гигантской магнитострикцией $[12,13]$.

3. Необычное для большинства металлов и сплавов поведение электросопротивления от температуры, так называемое „, $K$-состояние“ или „ $K$-эффект“ $[14,15]$.

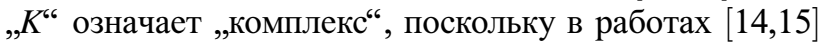
Thomas для объяснения эффекта сделал предположение о формировании во время отжига атомных комплексов. Позднее было доказано [16], что самой подходящей моделью для описания „K-состояния“ является модель дисперсного порядка с маленькими, высоко упорядоченными областями в менее упорядоченной матрице.

Фазовая диаграмма системы Fe-Al многократно уточнялась на протяжении многих лет, однако в настоящее время имеется качественное согласие между различными исследованиями природы фаз и переходов порядокбеспорядок в богатых Fe областях диаграммы [17-26]. На рис. 1 приведена богатая железом часть фазовой диаграммы сплавов системы железо-алюминий для концентраций $C_{\mathrm{Al}}$ от 0 до 60 at.\%, представленная в работах $[27,28]$. На этой диаграмме в ее низкотемпературной 


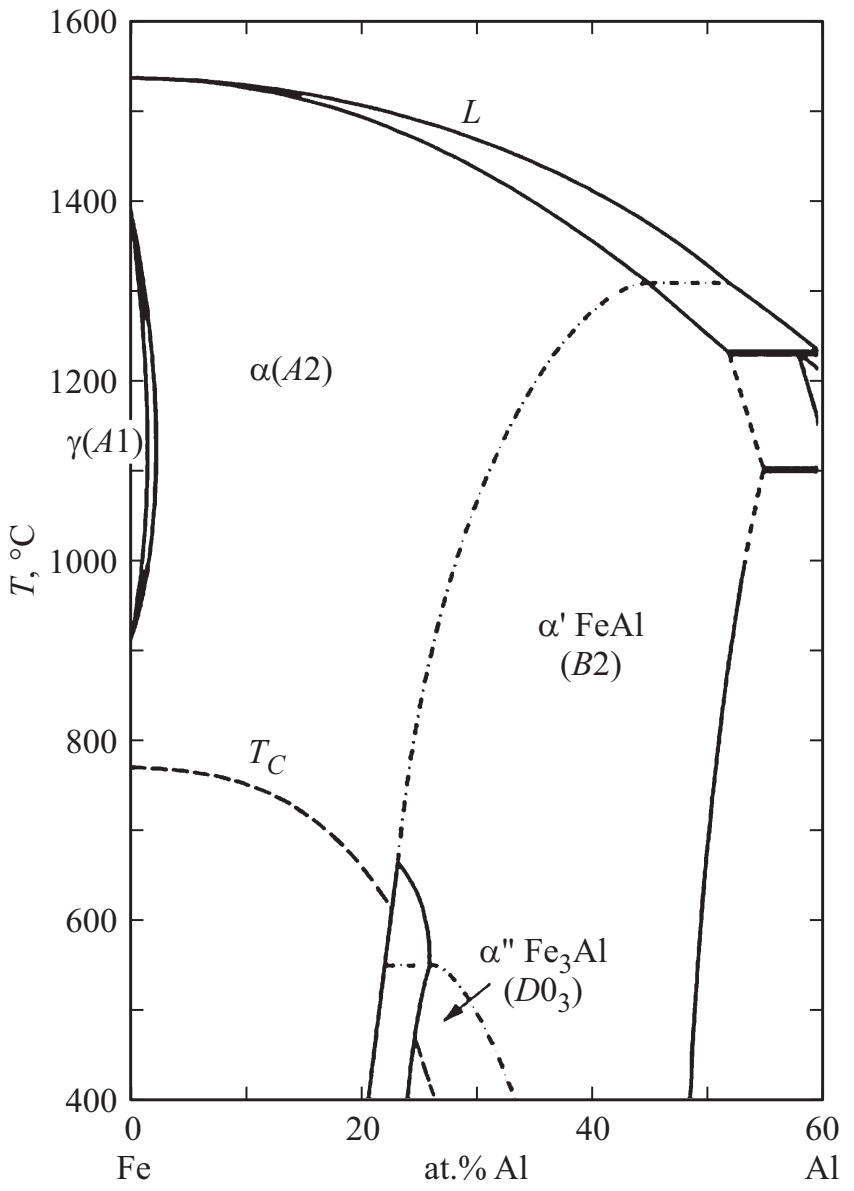

Рис. 1. Фазовая диаграмма системы железо-алюминий в богатой железом части. $L-$ область расплава, $\gamma(A 1)-$ область $\gamma$-фазы, $T_{C}$ - температура ферромагнитного перехода, точка Кюри сплава.

части примерно от 11 до 20 at.\% $\mathrm{Al}$ не показана область $K$-состояния, которая целиком входит в область $\alpha$-фазы или неупорядоченного твердого раствора замещения (структура $A 2$ ). Выше концентрации $C_{\mathrm{Al}} \approx 30$ at.\% имеются области фаз $\alpha^{\prime}$ и $\alpha^{\prime \prime}$ со стехиометрией $\mathrm{FeAl}$ и $\mathrm{Fe}_{3} \mathrm{Al}$ и структурой $B 2$ и $D 0_{3}$ соответственно [29]. На диаграмме сплошными линиями между 20 и 30 at.\% выделен сегмент, который соответствует области смешения двух фаз. В его верхней части смешиваются фазы $\alpha$ и $\alpha^{\prime}$, а в нижней, ниже примерно $550^{\circ} \mathrm{C},-$ фазы $\alpha$ и $\alpha^{\prime \prime}$.

Подробное описание равновесной фазовой диаграммы, приведенной на рис. 1, природы переходов и различных возможных механизмов фазовых превращений можно найти, например, в работах $[21,30]$. Здесь же необходимо отметить, что в соответствии с фазовой диаграммой и графиком зависимости коэффициента тетрагональной магнитострикции $\lambda_{100}$ от концентрации алюминия $C_{\mathrm{Al}}[31]$, приведенной на рис. 2, например, около концентрации $C_{\mathrm{Al}}=7$ at.\% имеет место неупорядоченный твердый раствор или $\alpha$-фаза.

Если связывать этот эффект просто с присутствием в сплаве отдельных атомов растворенной примеси, то, скорее всего, коэффициент $\lambda_{100}$ должен быть пропорционален $C_{\mathrm{Al}}$, примерно так, как на рис. 2 увеличивается $\lambda_{111}$ от $C_{\mathrm{Al}}$. В этой логике появилась простая идея, что если $\lambda_{100}$ увеличивается пропорционально количеству локально упорядоченных пар атомов алюминия, которое в свою очередь пропорционально $C_{\mathrm{Al}}^{2}$. Тогда атомы алюминия в ОЦК-решетке железа должны заполнять узлы не случайно, а одинаково упорядоченно в ближайшем окружении других атомов алюминия.

Поскольку данных о структурном состоянии сплавов системы железо-алюминий в области концентраций до $10 \%$ растворенного элемента в настоящее время практически нет, то рассмотрим всю область $\alpha$-фазы, т. е. примерно до 20 at.\% алюминия, которая включает в себя и область $K$-состояния. Так измерения электросопротивления образцов сплавов железа с 15.5-18.7 at.\% алюминия [32], которые предварительно были закалены в воду от температуры разупорядочения, а впоследствии продолжительно отжигались при разных температурах в интервале от 280 до $340^{\circ} \mathrm{C}$, показали, что структурные изменения в сплавах сопровождаются изменениями их электропроводности. Результаты детальных исследований кинетики ближнего упорядочения и его влияния

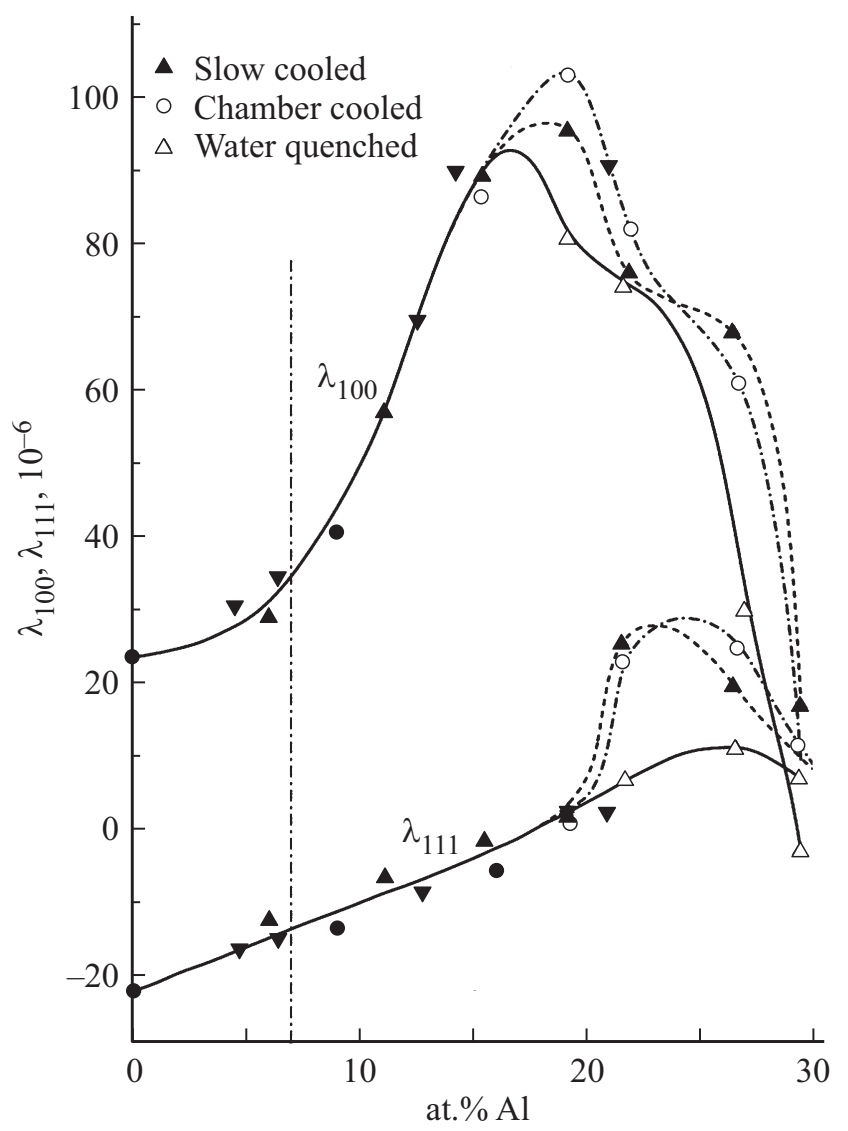

Рис. 2. Зависимости коэффициентов магнитострикции $\lambda_{100}$ и $\lambda_{111}$ от концентрации алюминия. Вертикальной штрихпунктирной линией отмечена концентрация алюминия 7 at.\%, которая соответствует концентрации алюминия в монокристаллических образцах, исследованных в настоящей работе. Источник - база данных [31]. 
на электропроводность лучше всего могут интерпретироваться с точки зрения теории дисперсного порядка, согласно которой во время отжига возникают, растут и стабилизируются области с высокой степенью порядка в гораздо менее упорядоченной матрице. При этом размер упорядоченной области не достигает наименьшей средней длины свободного пробега электрона, поэтому размер такой области может быть оценен как не превосходящий $\sim 1.6 \mathrm{~nm}[32]$.

Влияние растворения алюминия в $\alpha$-железе на механические свойства сплава было исследовано в работе Leamy etal. [33]. Были изготовлены и аттестованы 12 монокристаллических образцов железоалюминиевых сплавов с концентрацией алюминия от 4 до 40 at.\%, в которых затем измерялись скорости распространения поперечных и продольных ультразвуковых волн при разных температурах в пределах 77-300 К. Используя простые соотношения (см., например, в [33]) можно рассчитать три независимые упругие постоянные $C_{11}, C_{12}, C_{44}$ или их комбинации: модуль сдвига $C^{\prime}=\left(C_{11}-C_{12}\right) / 2$ и объемный модуль $\left(C_{11}+C_{12}\right) / 3$. Показано, что в неупорядоченных сплавах ( $\alpha$-фаза) добавление алюминия увеличивает $C_{44}$ и уменьшает $C^{\prime}$, тогда как в дальнеупорядоченных сплавах ( $\alpha^{\prime \prime}$-фаза) эти величины проявляют, соответственно, максимум и минимум при химическом составе $\mathrm{Fe}_{3} \mathrm{Al}$. Объемный модуль разбавленных сплавов уменьшается при добавлении алюминия и аномально увеличивается вблизи состава $\mathrm{Fe}_{3} \mathrm{Al}$ и проявляет максимум при 25 at.\% $\mathrm{Al}$.

Замеченные в работе [33] особенности поведения упругих постоянных в зависимости от состава были описаны Leamy в работе [34] в терминах простой модели центральных сил [35]. Модель основана на применении трех потенциальных функций парных взаимодействий $\mathrm{Fe}-\mathrm{Fe}, \mathrm{Fe}-\mathrm{Al}$ и $\mathrm{Al}-\mathrm{Al}$ с различными конфигурациями атомной пары с первым и вторым соседом, которые существуют в железоалюминиевых сплавах с различными типами и степенями дальнего порядка. Особенностью использованных в [34] потенциальных функций Morse является то, что энергии взаимодействия $\mathrm{Fe}-\mathrm{Fe}$ и $\mathrm{Fe}-\mathrm{Al}$ имеют минимальные отрицательные значения на межатомных расстояниях, соответствующих расстоянию до первых соседей в решетке сплава, в то время как энергия взаимодействия пар Al-Al минимальна на расстоянии, равном параметру ОЦК-ячейки. Следовательно, при растворении алюминия в железе в первой координационной сфере атома алюминия преимущественно располагаются атомы железа, во второй же координационной сфере атома алюминия может быть другой атом алюминия. В принципе, такая координация является локально упорядоченной и по мере увеличения концентрации алюминия может развиться в упорядоченные области $\alpha^{\prime}$ или В2 фазы (рис. 1).

Упругие константы, их температурная и концентрационная зависимости, установленные в работе Leamy et al. [33], использовались Clark et al. [13] для определения величины магнитоупругого взаимодействия в сплавах железа с 14.1, 16.6, 21.5 и 26.3 at.\% алюминия. Показано, что изменение константы магнитоупругой связи $\left(b_{1}\right)$ с температурой минимально для сплавов $\mathrm{Fe}-\mathrm{Al}$, имеющих разупорядоченную ОЦК-структуру (A2-фаза) $\left(C_{\mathrm{Al}}<19\right.$ at.\%). Напротив, в сплаве, обладающем упорядоченной $\left(\mathrm{DO}_{3}\right)$ структурой, имеет место аномальное уменьшение магнитоупругости при понижении температуры. В системе сплавов $\mathrm{Fe}-\mathrm{Al}$ константа $-b_{1}$ при комнатной температуре имеет максимум $12.3 \mathrm{MJ} / \mathrm{m}^{3}$ при 16.6 at.\% Al. Для сравнения в сплавах Fe-Ga при комнатной температуре максимальное значение $-b_{1}$ может достигать $\sim 15 \mathrm{MJ} / \mathrm{m}^{3}$ при $C_{\mathrm{Ga}} \approx 18$ at.\%. Наибольшее значение $\left|b_{1}\right|$, равное $13.4 \mathrm{MJ} / \mathrm{m}^{3}$, наблюдалось в сплаве c 16.6 at.\% Al при 77 K. При этом Clark et al. указывают на значительное влияние на величину константы магнитоупругого взаимодействия структурного состояния сплава, которое они определяют по его термической предыстории [13].

Общие представления о формировании ближнего порядка в разбавленных твердых растворах даны в работе Ивероновой и Кацнельсона [36] на основе краткого обзора основных результатов теоретических и экспериментальных исследований локального упорядочения в сплавах. Анализ экспериментов, проведенных на деформированных, закаленных и слабо отожженных после деформации или закалки от высоких температур образцах, показал, что установление равновесного ближнего порядка происходит немонотонно. Это явление объясняется образованием при кратковременном отжиге вблизи искаженных участков решетки областей с более высокой степенью ближнего порядка по сравнению со средней по всему образцу.

Методом диффузного рассеяния рентгеновских лучей изучено изменение параметров ближнего порядка при изохронном отжиге упорядоченных, закаленных от $1000^{\circ} \mathrm{C}$, деформированных при комнатной температуре образцов железоалюминиевых сплавов с 8 и 10 at.\% Al [37]. На основании полученных данных сделан вывод, что при выбранных термообработках ближний порядок, образующийся в указанных сплавах, является, по-видимому, однородным, но ничего не сказано о характере ближнего упорядочения [37].

При кратковременном низкотемпературном отжиге сплава $\mathrm{Fe}-\mathrm{Al}(15.3$ ат.\% Al) после пластической деформации и закалки после отжига при высокой температуре обнаружен рост степени ближнего порядка и размерного эффекта [38]. Величина первого параметра ближнего порядка Уоррена-Каули $\left(\alpha_{1}\right)$ не находит объяснения в рамках теории однородного упорядочения. Показано, что аномально большое значение $\alpha_{1}$ может быть объяснено, если предположить, что в твердом растворе возникают области, обогащенные и обедненные Al, степень ближнего порядка в которых достаточно высока. С этой гипотезой согласуются наблюдаемые в работе понижение фона и повышение размерного эффекта. В образцах сплава $\mathrm{Fe}_{3} \mathrm{Al}$ (около 25 at.\% $\mathrm{Al}$ ), закаленных от $600^{\circ} \mathrm{C}$, обнаружено ближнее упорядочение по типу 
FeAl. В образцах, деформированных после медленного охлаждения слитка, - по типу $\mathrm{Fe}_{3} \mathrm{Al}$.

В работе [39] изучался ближний порядок в сплавах с 16-27 at.\% Al после отжига в области температур, где наблюдается впадина на кривых зависимости теплоемкости от температуры. По изменению интенсивности диффузного рассеяния рентгеновских лучей в области сверхструктурных максимумов (100) и (0.5 0.50 .5$)$ (в индексации для $D 0_{3}$ это максимумы (200) и (111) соответственно) сделан вывод о том, что возникновение впадины в диапазоне $190-300^{\circ} \mathrm{C}$ для сплава 16.3 at.\% $\mathrm{Al}$ обусловлено существенным ростом степени ближнего порядка при нагреве. В закаленном сплаве с 19.2 at.\% $\mathrm{Al}$ уже в процессе закалки возникают области с дальним порядком. При этом сверхструктурное отражение (100) является достаточно узким, в то время как отражение (0.5 0.50 .5 ) чрезвычайно размыто. Дано объяснение такому характеру расширения линий (области В2 большого размера, в которые вкраплены домены (кластеры) с $D 0_{3}$-упорядочением) и показано, что размер упорядоченных по типу $\mathrm{Fe}_{3} \mathrm{Al}\left(\mathrm{DO}_{3}\right)$ доменов в закаленном сплаве не превышает 4-5 nm. В области температур, соответствующих минимуму на кривой теплоемкости, размер упорядоченных областей увеличивается.

Монокристаллические образцы железоалюминиевых сплавов, содержащие от 5 до 29 at.\% Al, были впервые исследованы в работах Власовой и Ивероновой [40,41], в которых анализировалось распределение интенсивности диффузного рассеяния, зафиксированное на фотопленке. Для твердых растворов показано, что диффузные максимумы расположены несимметрично относительно узлов обратной решетки из-за размерного эффекта вследствие большого различия в размерах атомов железа и алюминия. Раствор может состоять из небольших обогащенных алюминием областей со структурой $D 0_{3}$, случайно распределенных в неупорядоченной матрице. Области фазы $\alpha^{\prime \prime}$ настолько малы, что ближний порядок, вероятно, не выходит за пределы третьей координационной сферы [41].

Результаты рентгенодифракционных исследований структуры и фазового состава монокристаллов сплава, содержащих от 14 до 23 at.\% алюминия, подвергнутых отжигу разной продолжительности от одного часа до 74ч и закалке в воду, представлены в работах Epperson и Spruiell $[42,43]$. В качестве основного вывода из этих исследований авторы отметили обнаружение при концентрации алюминия 21.3 и 22.8 at.\% и температурах от 500 до $550^{\circ} \mathrm{C}$ области, в которой сосуществуют в равновесии стехиометрические фазы $\mathrm{Fe}_{3} \mathrm{Al}$ и $\mathrm{FeAl}$ с дальним порядком типа $D_{3}$ и $B 2$ соответственно. В то же время дальний порядок не наблюдался в сплавах, содержащих 15.8 и 14.0 at.\% Al, но в диффузном рассеянии от них наблюдались значительные колебания интенсивности.

Для анализа диффузного рассеяния от монокристаллов были использованы трехмерные аналитические методы, разработанные Sparks и Borie [44], которые позволяют разделить измеренную интенсивность диффузного рассеяния на вклады, из которых могут быть отдельно определены трехмерные параметры локального порядка и атомных смещений. Полученные результаты показали, что сплавы железо-алюминий, закаленные от $850^{\circ} \mathrm{C}$, являются локально упорядоченными. По мере увеличения концентрации алюминия проявляется тенденция к формированию сверхрешетки типа $\mathrm{DO}_{3}$ в ближнем порядке, хотя имеется также большое число пар Al-Al, являющихся вторыми ближайшими соседями [43].

Комплексные исследования монокристалла железоалюминиевого сплава с содержанием алюминия 19.5 at.\% были выполнены Pierron-Bohnes et al. [45,46]. Дифракционными методами гамма-излучения и нейтронов был измерен коэффициент затухания интенсивности брэгговских отражений из-за тепловых и статических смещений атомов в широком температурном диапазоне: от 5 до $1464 \mathrm{~K}$, откуда получена оценка среднего статического смещения атомов $(0.0032 \mathrm{~nm})$, и определена температура Дебая $(476 \pm 22) \mathrm{K}$. Ближний порядок в парамагнитном состоянии при температурах между 973 и $1573 \mathrm{~K}$ был исследован с помощью диффузного рассеяния нейтронов [47]. Параметры ближнего порядка и атомных смещений определялись при согласовании теоретического сечения рассеяния в формулировке Borie и Sparks [48] и экспериментально измеренных интенсивностей диффузного рассеяния. Оказалось, что для описания ближнего порядка наиболее важными параметрами являются первый $\alpha_{1}$ (для первой координационной сферы) и третий $\alpha_{3}$. Они имеют противоположные знаки, что указывает на сильное отталкивающее взаимодействие между одинаковыми атомами (узлы в ячейке 000 и 0.50 .50 .5$)$ и притягивающее взаимодействие между одинаковыми третьими соседями (000 и 110). Эти значения параметров $\alpha_{1}$ и $\alpha_{3}$ следует связать с заселенностью узлов разных подрешеток в фазах $\mathrm{DO}_{3}$ и $\mathrm{B2}$. В фазе $\mathrm{DO}_{3}$, имеющей стехиометрию $\mathrm{Fe}_{3} \mathrm{Al}$, атомы алюминия находятся между собой только в позициях третьих соседей, нет ни первых и ни вторых соседей Al-Al. В фазе $B 2(\mathrm{FeAl})$ они находятся в положениях 2-х и 3-х соседей и нет пар Al-Al первых соседей. Полученные в работе [47] параметры $\alpha_{1}$ и $\alpha_{3}$, скорее всего, указывают на ближний порядок $D 0_{3}$-типа, но положительное значение параметра $\alpha_{2}$ в несколько раз меньшее, чем $\alpha_{3}$, свидетельствует и о присутствии пар атомов Al-Al в качестве вторых соседей или ближнего порядка $B 2$-типа. Уменьшение параметров ближнего порядка с увеличением температуры означает, что ближний порядок постепенно нарушается. Эти результаты сравниваются с результатами, полученными из анализа интенсивностей рентгеновского диффузного рассеяния на том же сплаве, закаленном в воду после отжига в ферромагнитном состоянии при $772 \mathrm{~K}$ (или $499^{\circ} \mathrm{C}$ ) [46]. В работе [46] было показано, что размер области ближнего порядка очень мал. Наибольшее значение амплитуды смещения получено для первых трех координационных сфер и так же быстро, как параметр порядка, уменьшается с увеличением радиуса координационной сферы. 
По результатам исследований $[46,47]$ было сделано важное заключение о том, что в системе железоалюминий существует сильная взаимосвязь между магнитными и химическими взаимодействиями. В частности, энергия эффективного парного взаимодействия между первыми ближайшими соседями в ферромагнитной фазе уменьшается вдвое по сравнению с парамагнитной фазой, что резко снижает степень ближнего порядка.

В экспериментах по рассеянию нейтронного излучения, которые проводились на монокристалле сплава FeAl c 20 at.\% Al in situ при температурах от 550 до $800^{\circ} \mathrm{C}$ [49], выявлена не только асимметрия сверхструктурных пиков, но еще более выраженная анизотропия диффузного рассеяния вокруг пика (110). По мнению Schweika et al., наблюдаемые особенности диффузного рассеяния объясняются увеличением межатомных расстояний вблизи атомов алюминия. Интенсивность сверхструктурного пика (100) при увеличении температуры в ферромагнитной области от 550 до $650^{\circ} \mathrm{C}$ уменьшается незначительно. В парамагнитной фазе при $800^{\circ} \mathrm{C}$ зависимость интенсивности диффузного рассеяния от угла дифракции не меняется, а величина интенсивности пиков значительно уменьшается. Эти данные соответствуют представлению о характере ближнего упорядочения в сплавах железо-алюминий, а результаты следующей работы Schweika [50] явно противоречат ему. Приведенное в [50] двумерное распределение интенсивности диффузного рассеяния в плоскости (110) от монокристалла $\mathrm{Fe}_{0.8} \mathrm{Al}_{0.2}$, измеренное при температуре, не превосходящей $380^{\circ} \mathrm{C}$, показывает существенное ослабление интенсивности в направлении (100) и одновременно появление довольно узкого пика в положении (0.5 0.5 0.5). Если интенсивности отражений $(0.50 .50 .5)$ и (100) соотносятся как $2: 1$, то это указывает на $D 0_{3}$-упорядочение, присутствие только пика (100) - на B2-упорядочение. Присутствие только одного пика (0.5 0.50 .5$)$ указывает на химическое упорядочение B32-типа, при котором пары атомов алюминия являются ближайшими соседями. Детальное описание и сравнение всех трех структур дано в статье [51]. На основании результатов исследований методом рентгеновской дифракции сплавов с 14.6, 17.3 и 19.1 at.\% $\mathrm{Al}$ Becker и Schweika [51] внесли изменения в A2-область фазовой диаграммы (рис. 1), добавив при температуpax меньших $350^{\circ} \mathrm{C}$ и концентрациях алюминия от 10 до 20 at.\% область с В32-упорядочением. Из ширины пика $(0.50 .50 .5)$ был определен средний размер областей B32-фазы: от 6 до $8 \mathrm{~nm}$. С ростом температуры ширина пика, неизменная до $\sim 300^{\circ} \mathrm{C}$, увеличивается, а интенсивность снижается до уровня фона. Выше $350^{\circ} \mathrm{C}$ диффузное рассеяние соответствует состоянию с ближним упорядочением. Приводится подробное обсуждение возможных причин превращения фазы $A 2$ в B32. Предполагается, что в богатых железом ферромагнитных сплавах магнитное взаимодействие между моментами железа должно стабилизировать фазу В32 [51].

В работе [51] Becker и Schweika наблюдали вблизи узлов (111) и (100) широкие диффузные пики слабой интенсивности. Диффузное рассеяние асимметрично с увеличением интенсивностей в сторону меньших углов, что согласуется с предыдущими наблюдениями и может быть объяснено модуляцией рассеяния ближнего порядка из-за размерных эффектов и локальных смещений. Интенсивности вблизи (111) и (100) практически не изменялись в пределах температурного интервала до $460^{\circ} \mathrm{C}$.

Schönfeld et al. в 2006 г. [52] представили результаты рентгенодифракционных исследований монокристаллов сплава железо-алюминий с 19.4 и 18.2 at.\% Al. Образцы предварительно были гомогенизированы продолжительным отжигом при $1100^{\circ} \mathrm{C}$ и закалены в ледяном рассоле. Затем они подвергались старению каждый раз по $24 \mathrm{~h}$ сначала при температуре $450^{\circ} \mathrm{C}$, снижая температуру с шагом в $25^{\circ}$ до $325^{\circ} \mathrm{C}$ - температуры, которая по данным Schweika et al. является оптимальной для формирования областей фазы B32 [51]. После каждой термообработки измерялось диффузное рассеяние при радиальном сканировании через позиции (1.5 1.5 1.5) и (111). Сразу после гомогенизации и закалки наблюдается почти плоское распределение интенсивности около (1.5 1.5 1.5), а асимметричная форма профиля интенсивности около (111) соответствует рассеянию, обусловленному размерным эффектом. При уменьшении температуры старения наблюдается увеличение интенсивности рассеяния в обоих положениях. После старения при $325^{\circ} \mathrm{C}$ интенсивность еще больше увеличивалась в обоих положениях, в то время как ширина пиков уменьшается. Интегральные интенсивности после применения зависящих от вектора рассеяния поправок (на фактор атомного рассеяния, поляризационный коэффициент Лоренца и фактор Дебая-Валлера) оказались в соотношении близком к $2: 1$, что характерно для сверхструктуры $\mathrm{DO}_{3}$.

Суммируя результаты структурных исследований сплавов системы железо-алюминий в $\alpha$-области фазовой диаграммы (рис. 1), можно сделать вывод о том, что выше температуры Кюри имеются признаки тенденции к возникновению локального упорядочения $B 2$-типа. При низких температурах наблюдается тенденция к установлению ближнего порядка $D 0_{3}$-типа. Появление $B 32$-упорядочения является весьма сомнительным и требует дополнительных исследований [52].

Аналогичные тенденции при увеличении концентрации растворенного элемента и повышении температуры наблюдаются в фазовой диаграмме магнитомягких железокремнистых сплавов [53]. Результаты исследований локальной структуры кристаллов железо-кремний, содержащих от 5 до 10 at.\% $\mathrm{Si}$, с помощью рентгеновской дифракции и ЯГР-спектроскопии приведены в работах [54-57]. Впервые показано, что для всех концентраций кремния характерно ближнее упорядочение $B 2$-типа в ОЦК-решетке сплавов, которое в случае $x \geq 0.08$ сосуществует с кластерами $D 0_{3}$-фазы. Ближний порядок атомов в B2-кластерах сопровождается их смещением из узлов идеальной решетки, в то время как в 
$D 0_{3}$-фазе искажения решетки не отмечены. Увеличение концентрации кремния от 8 до 10 at.\% приводит к значительному росту размеров областей $D 0_{3}$-фазы и их суммарного объема и при сохранении небольшого количества $B 2$-кластеров [57]. В2-кластер можно представить как ядро из двух соседних $B 2$-ячеек, имеющих общую грань, окруженное растянутыми ячейками $\alpha$-железа [55]. Из-за этого $B 2$-кластеры являются более протяженными вдоль одной из осей легкого намагничивания $\langle 100\rangle$. Следовательно, в фазовой диаграмме сплавов $\mathrm{Fe}-\mathrm{Si}$ граница между неупорядоченным твердым раствором ( $\alpha$-фазой) и двухфазной областью с доменами $D 0_{3}$-фазы имеет место при концентрациях растворенного элемента на 12-14 at.\% меньших, чем в диаграмме сплавов железоалюминий (рис. 1).

Для выяснения механизмов упорядочения растворенных атомов в $\alpha$-железе были проведены первопринципные расчеты полной энергии и величины атомных смещений в окрестности атома растворенного элемента $[58,59]$. Показано, что наибольшие отрицательные смещения $(\sim-0.7 \%)$ около атома $\mathrm{Si}$ получены для атомов $\mathrm{Fe}$, находящихся в положении вторых соседей. В окружении атома алюминия в первой координационной сфере расстояния увеличиваются $(+1.4 \%)$, во второй - уменьшаются $(-0.7 \%)$. Образование пар $\mathrm{Si}-\mathrm{Si}$ или Al-Al вторых ближайших соседей приводит к локальному тетрагональному искажению решетки, а их упорядочение, в принципе, может приводить к макроскопической тетрагональности образца.

В приближении когерентного потенциала с использованием метода функций Грина рассчитаны энергии парных и многочастичных взаимодействий в зависимости от магнитного состояния и проведено методом Монте-Карло моделирование формирования областей с ближним порядком в сплавах $\mathrm{Fe}-\mathrm{Si}$ и $\mathrm{Fe}-\mathrm{Al}[60,61]$. Показано, что энергия эффективного взаимодействия растворенных атомов в ОЦК-железе существенно зависит от магнитного состояния матрицы. В ферромагнитном состоянии (при температурах ниже $T_{C}$ ) энергетически предпочтительными являются конфигурации, в которых два атома $\mathrm{Si}$ (или $\mathrm{Al}$ ) находятся в положении 3-х или 4-х соседей. В парамагнитном состоянии энергия пары $\mathrm{Si}-\mathrm{Si}$ (или Al-Al), как вторых соседей, значительно понижается. В результате, ближний порядок типа B2 формируется при температурах, больших $T_{C}$, и фиксируется при закалке, в то время как в ферромагнитном состоянии равновесным является ближний порядок типа $D 0_{3}$. Полученные результаты позволяют объяснить наблюдаемые экспериментально структурные особенности сплава в зависимости от состава и температуры [60].

Если сопоставить фазовую диаграмму системы железо-алюминий (рис. 1) и кривую зависимости константы тетрагональной магнитострикции $\lambda_{100}$ от концентрации алюминия (рис. 2), то наибольший рост магнитострикции, пропорциональный квадрату концентрации $C_{\mathrm{Al}}$, имеет место в области неупорядоченного твердого раствора $A 2$ ( $\alpha$-фазы). Граница, которая соответствует переходу к упорядоченному состоянию, возникающему выше 21 at.\% Al, примерно совпадает с максимумом и началом падения величины магнитострикции $\lambda_{100}$. Очевидно, что высокая магнитострикция обусловлена особенностями кристаллической структуры. Поскольку механизм формирования магнитострикции в сплавах железа с алюминием и в сплавах с галлием до сих пор до конца не выяснен, то информация о структуре и характере ближнего упорядочения в богатых железом сплавах с алюминием имеет важное значение для выяснения роли этого механизма.

В настоящей работе методом рентгеновской дифракции исследуются монокристаллические образцы сплава железо-алюминий, содержащего около 7 at.\% алюминия. Концентрация алюминия находится в области линейной зависимости параметра ОЦК-решетки и рассчитанной из него плотности кристалла от концентрации $C_{\mathrm{Al}}$. Кроме того, в интервале $0<C_{\mathrm{Al}}<0.27$ наблюдается линейное снижение упругого модуля $C_{11}$, которое в какой-то мере объясняет как рост магнитострикции $\lambda_{100}$ в интервале $C_{\mathrm{Al}}$ от 0 до 0.17 , так и достижение значения $\lambda_{100}=90$ ррт при $C_{\mathrm{Al}} \approx 0.17$.

Целью настоящей работы является изучение особенностей локальной атомной структуры железоалюминиевого сплава в области неупорядоченного твердого раствора $A 2$ фазовой диаграммы бинарного сплава $\mathrm{Fe}-\mathrm{Al}$ (рис. 1), который был подвергнут отжигу в парамагнитном состоянии при температуре $850^{\circ} \mathrm{C}$, превышающей точку Кюри сплава, с последующей закалкой в воду, а также отжигу в ферромагнитном состоянии при температуре $450^{\circ} \mathrm{C}$, которая не превышает $T_{C}$, с последующим медленным охлаждением до комнатной температуры.

\section{2. Образцы и методика эксперимента}

Рентгеноструктурные исследования проводились на монокристаллических образцах сплава $\mathrm{Fe}-7$ at.\% $\mathrm{Al}$ и монокристалле чистого железа в качестве своеобразного „эталона“ в измерениях. Образцы сплава были вырезаны из монолитного кристалла, выращенного про методу Бриджмена, в виде тонких дисков (толщина $0.3 \mathrm{~mm}$, диаметр 8-9 mm) с „госсовской“ ориентацией кристаллографических осей, когда ось [110] и легкая ось [001] лежат в плоскости диска.

Образцы сплава были подвергнуты рафинирующему вакуумному отжигу при температуре $1050^{\circ} \mathrm{C}$ в течение $4 \mathrm{~h}$. Первый образец был снова отожжен в течение одного $\mathrm{h}$ при $T_{\mathrm{an}}=450^{\circ} \mathrm{C}$, не превосходящей температуру Кюри сплава $\left(T_{C}=750^{\circ} \mathrm{C}\right)$, и медленно охлажден с печью. Второй образец после десятиминутного отжига $T_{\text {an }}=850^{\circ} \mathrm{C}$ в парамагнитном состоянии был подвергнут закалке в воду (скорость закалки $\sim 400^{\circ} \mathrm{C} / \mathrm{s}$ ).

Дополнительно был приготовлен монокристаллический образец железа в виде тонкой пластинки с плоскостью, близкой к кристаллографической плоскости (113). Содержание углерода в нем не превосходило 0.06 wt.\%. Профили интенсивности диффузного рассеяния от монокристалла $\mathrm{Fe}$, измеренные при сканировании вдоль 


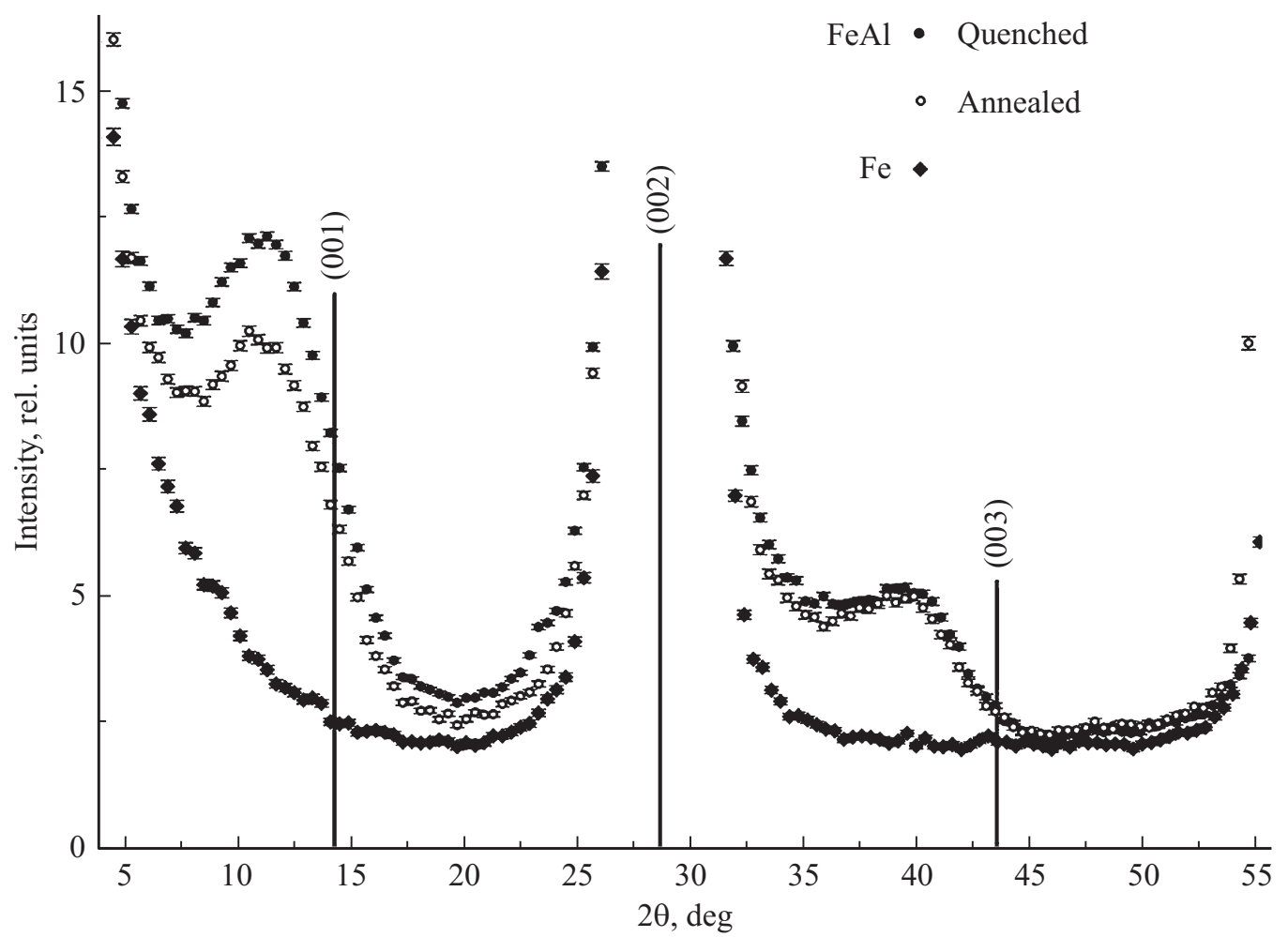

Рис. 3. Угловое распределение интенсивности при $\theta-2 \theta$-сканировании вдоль направления [001] в монокристаллах $\alpha$-железа и сплава железо-алюминий ( 7 at.\% $\mathrm{Al})$. Вертикальными прямыми линиями и соответствующими индексами отмечены расчетные позиции брэгговского (002) и сверхструктурных (001) и (003) рефлексов.

различных кристаллографических направлений, сравнивали с аналогичными сканами для образцов сплава. Это позволило надежно выделить вклад, обусловленный рассеянием на областях с локальным упорядочением примесных атомов Al, а также исключить вклад рассеяния от характерных для ОЦК-решетки диффузных плоскостей и стержней, обусловленных тепловым движением атомов [62].

Измерения проводились при комнатной температуpe на четырехкружном лабораторном дифрактометре (ПИЯФ НИЦ „Курчатовский институт“') в геометрии на просвет. Характеристическое излучение рентгеновской трубки с Мо анодом $(\lambda=0.071 \mathrm{~nm})$ монохроматизировалось с помощью кристалла пиролитического графита. Рассеянное излучение регистрировалось энергодисперсионным $\mathrm{Si}(\mathrm{Li})$ детектором [55], что позволяет значительно улучшить соотношение сигнал/фон.

\section{3. Результаты и обсуждение}

В дифрактограммах, измеренных при $\theta-2 \theta$ сканировании вдоль определенных кристаллографических направлений, от сплава $\alpha$-FeAl (7 at.\% Al), также, как и от чистого $\alpha$-железа, имеющих ОЦК-решетку, наблюдаются дифракционные отражения с четной суммой индексов $h, k, l$, например, (110), (200), (211), (220), (310), (400) и др. Вклад В2-фазы проявляется в виде слабых широких (диффузных) пиков с максиму- мом вблизи расчетного положения для отражений с нечетной суммой индексов $h+k+l$. В эти же пики дает вклад и $D 0_{3}$-фаза, но поскольку ее элементарная ячейка удвоена вдоль кристаллографических осей $\langle 100\rangle$ ОЦК-решетки, то появляются сверхструктурные пики (рефлексы) с полуцелыми индексами $h=n / 2, k=m / 2$ и $l=p / 2(n, m, p$ - целые нечетные числа) например, (0.5 0.50 .5 ), (1.5 0.50 .5 ), (1.5 1.50 .5 ), (1.5 1.5 1.5) и т. п.

Интенсивность основных брэгговских пиков мало меняется при переходе от $\alpha$-железа к $\mathrm{Fe}-\mathrm{Al}$ сплаву, но их положение в дифрактограмме смещается в сторону меньших углов рассеяния, что соответствует увеличению параметра ОЦК-ячейки $а$ при растворении алюминия [63]. В сплавах железа с кремнием, наоборот, с увеличением концентрации кремния параметр ОЦКрешетки уменьшается, поскольку атомный радиус $\mathrm{Si}$ меньше, чем у Al. Из положения пиков в дифрактограмме можно вычислить параметр ОЦК-решетки для сплава с 7 at.\% Al, $a=0.2879(1)$ nm. В пределах одной стандартной ошибки он одинаков для обоих образцов.

При сканировании обратного пространства вдоль направлений [001], [111] в промежутках между очень интенсивными брэгговскими рефлексами обнаружены широкие диффузные пики, которые наблюдаются в случае $\mathrm{Fe}-\mathrm{Al}$ сплава при концентрации алюминия 7 at.\% и после его закалки от температуры $850^{\circ} \mathrm{C}$, превышающей $T_{C}$, и после отжига в ферромагнитном состоянии. Для примера на рис. 3 приведено угловое распределение интенсив- 


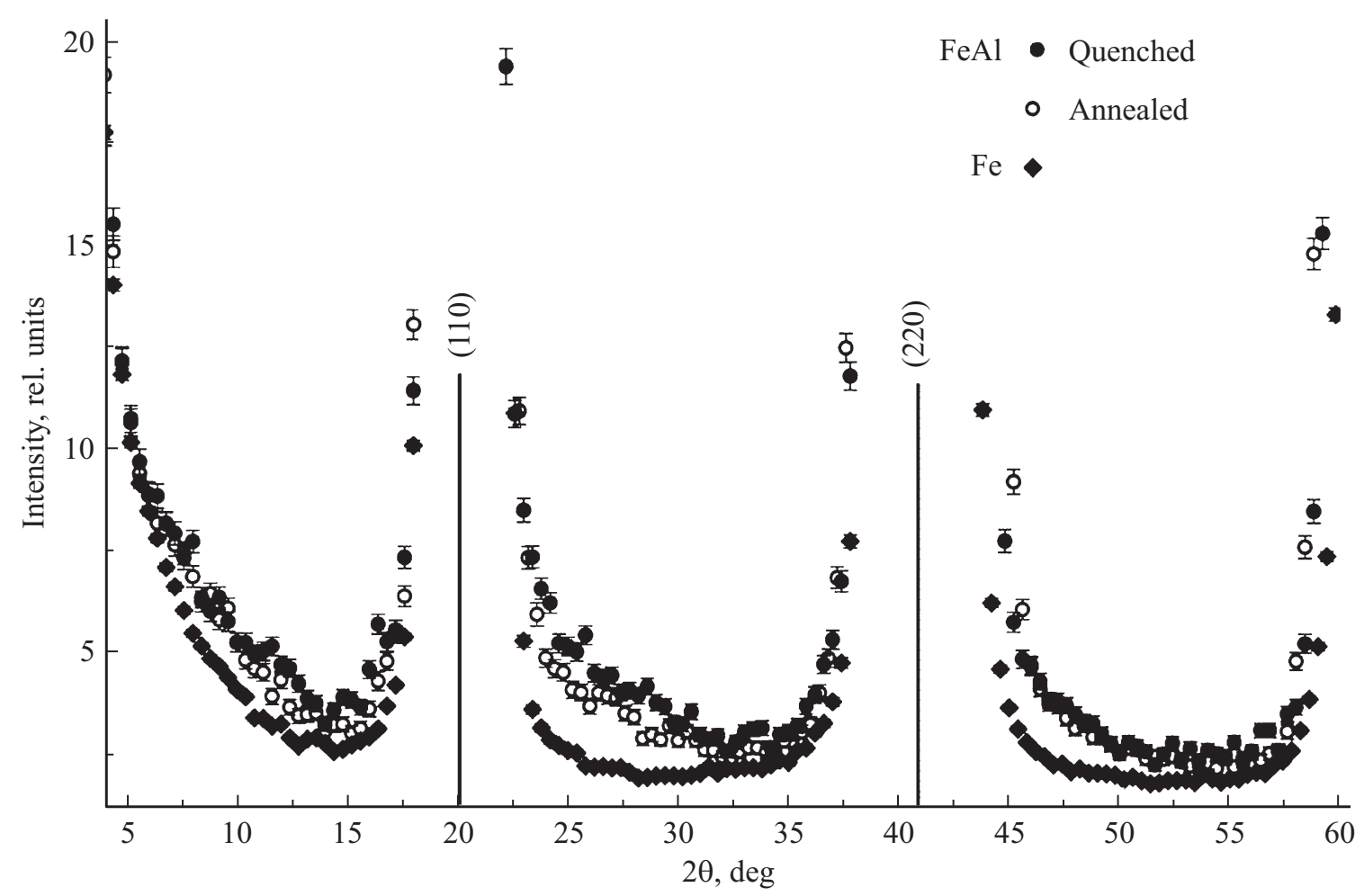

Рис. 4. Угловое распределение интенсивности при $\theta-2 \theta$-сканировании вдоль направления [110] в монокристаллах $\alpha$-железа и сплава железо-алюминий ( 7 at.\% Al). Вертикальными линиями показаны расчетные положения брэгговских рефлексов.

ности при $\theta-2 \theta$-сканировании вдоль направления [001] между узлами обратного пространства (000)-(002) и (002)-(004) для образцов сплава и чистого железа. Как видно из рисунка, в случае монокристалла железа скан не содержит никаких особенностей.

В сканах вдоль [001] от монокристаллов сплава наблюдаются диффузные пики, максимум которых сдвинут в сторону меньших углов рассеяния от расчетных положений для $(001)$ в интервале $(000)-(002)$ и для $(003)$ в интервале $(002)-(004)$. Диффузные пики вблизи (001) и (003) с учетом разной интенсивности фона на углах $2 \theta<25^{\circ}$ отличаются мало.

Появление в дифрактограммах сплава сверхструктурных диффузных пиков $(h k l)$ с нечетной суммой $h+k+l$ свидетельствует о возникновении ближнего упорядочения атомов примеси В2-типа. Смещение максимума из расчетного положения может быть обусловлено деформацией решетки в окружении растворенных атомов алюминия. Аналогичное смещение сверхструктурных пиков наблюдалось в железокремнистых сплавах [54,55]. Особенности диффузного рассеяния в сплавах $\mathrm{Fe}-\mathrm{Si}$ объяснялись присутствием кластеров, состоящих из двух ОЦК-ячеек, которые центрированы атомами кремния и имеют общую грань. Моделирование структуры, состоящей из хаотично ориентированных кластеров $B 2$-типа, окруженных деформированными ОЦК-ячейками железа, давало хорошее (на качественном уровне) согласие расчетных и экспериментально наблюдаемых картин диффузного рассеяния [55,64].
Из полной ширины пика на его полувысоте можно получить оценку среднего размера кластера B2-фазы [65]. С этой целью методом наименьших квадратов (МНК) сверхструктурные пики (001) и (003) аппроксимировались функцией Гаусса, откуда и была определена ширина пика. Размер кластера в закаленном и отожженном образцах примерно 6.0-7.5 А. Это несколько больше длины двух ОЦК-ячеек железа $(a \approx 2.9 \AA)$, что соответствует представлению о формировании вклада в диффузное рассеяние от хаотично распределенных по кристаллографическим направлениям $\langle 100\rangle B 2$ кластеров из двух $B 2$-ячеек и от деформированного ближайшего окружения.

Для сплавов в $\theta-2 \theta$-сканах вдоль оси [110] наблюдается асимметрия диффузного рассеяния между основными структурными пиками в сравнении с фоном от монокристалла железа, что видно на рис. 4, где приведено угловое распределение интенсивности между сильными брэгговскими пиками (110), (220) и (330).

При сканировании в направлении [111] в угловом распределении интенсивности рассеяния от $\alpha$-Fe, кроме сильного (222), наблюдаются (рис. 5) четыре очень широких пика, вклад в которые дает тепловое диффузное рассеяние (TDS), обусловленное фононными колебаниями цепочек атомов вдоль оси $\langle 111\rangle$ кристалла [62]. В аналогичных сканах от образцов сплава виден вклад рассеяния на кластерах с $D 0_{3}$-типом упорядочения атомов, которому соответствуют диффузные пики с полуцелыми индексами (0.5 0.5 0.5) и (1.5 1.5 1.5). 


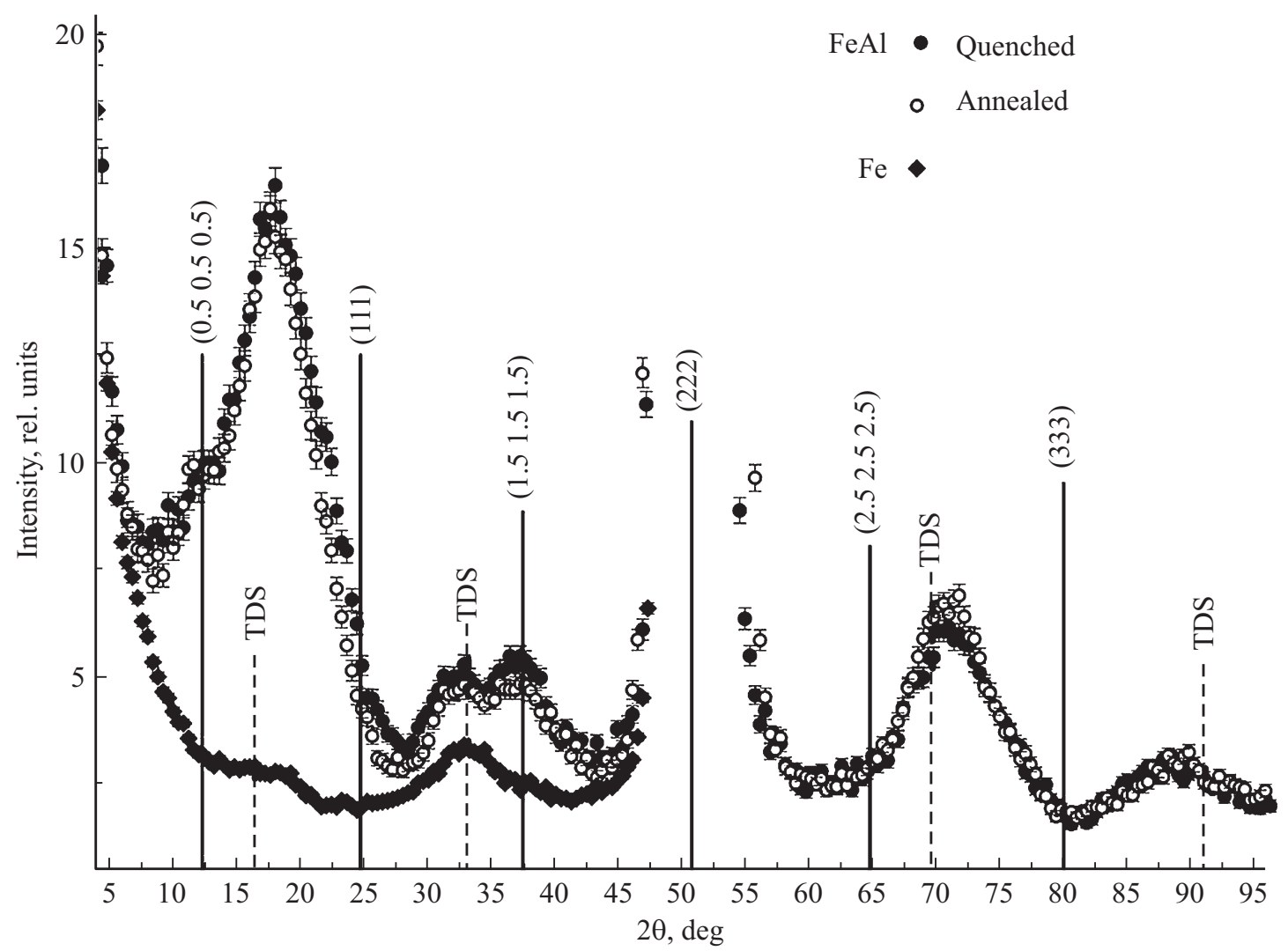

Рис. 5. Угловое распределение интенсивности при $\theta-2 \theta$-сканировании вдоль направления [111] в монокристаллах сплава железоалюминий $(7 \mathrm{at} . \% \mathrm{Al})$. $(h k l)$ - расчетное положение сверхструктурных пиков и брэгговского пика (222); TDS - pacчетное положение максимумов теплового диффузного рассеяния, обусловленного колебаниями цепочек атомов вдоль $\langle 111\rangle$. В интервале углов между узлами (000) и (222) приведена интенсивность рассеяния от монокристалла железа.

Заметное увеличение интенсивности TDS пика на угле $2 \theta \sim 18^{\circ}$ скорее всего связано с вкладом рассеяния на B2-кластерах, величина которого, как видно из рис. 3, быстро уменьшается с ростом $2 \theta$ примерно как квадрат форм-фактора атомов $\mathrm{Fe}$ и $\mathrm{Al}$.

Для образцов сплава участок дифрактограммы между узлами (000) и (222) разложен на отдельные пики с помощью метода наименьших квадратов. Из ширины пиков получена оценка размеров $B 2$ - и $D 0_{3}$-кластеров, равная примерно двум параметрам ОЦК-ячейки.

На полученном в эксперименте распределении интенсивности диффузного рассеяния в плоскости (110) от образца, предварительно отожженного при температуре $450^{\circ} \mathrm{C}$ в ферромагнитном состоянии в течение одного часа, видны (рис. 6) основные особенности, которые обсуждались выше. Вблизи узлов с нечетной суммой индексов $h, k$ и $l$, а именно (001), (111), (122), (311) и (322), присутствуют смещенные в направлении меньших углов диффузные пики, обусловленные рассеянием на $B 2$-кластерах. В узлах с полуцелыми индексами $h, k$ и $l$, например, (0.5 0.50 .5$),(1.51 .51 .5)$, (0.5 0.51 .5$)$ и (1.5 1.50 .5$)$, имеются слабые наплывы интенсивности, соответствующие рассеянию на областях с $D 0_{3}$-упорядочением, из которых два первых отчетливо видны в скане на рис. 5. Объемная доля областей типа $D 0_{3}$ мала, а их средний размер сопоставим с размером одной элементарной ячейки $D 0_{3}$-фазы, т.е. около $0.58 \mathrm{~nm}$. Распределение интенсивности рассеяния от второго образца не отличается существенно от картины на рис. 6, поэтому не приводится.

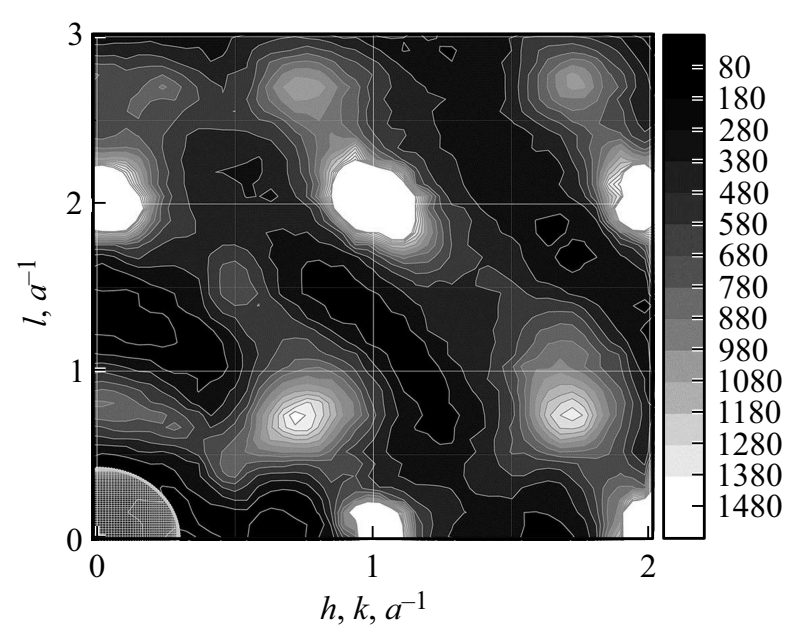

Рис. 6. Распределение интенсивности диффузного рассеяния в плоскости (110) от монокристаллического образца сплава железо-алюминий $(7$ at. $\% \mathrm{Al})$, предварительно подвергнутого отжигу в ферромагнитном состоянии. 


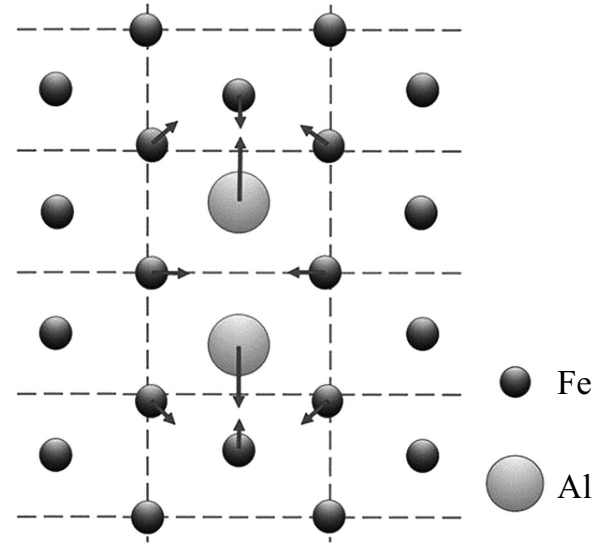

Рис. 7. Схема деформации кластера, т. е. смещений входящих в него атомов $\mathrm{Al}$ и $\mathrm{Fe}$, в плоскости (11̄0). Атомы алюминия показаны большими окружностями, атомы железа - меньшими. Стрелками - направления смещения атомов, длина стрелок пропорциональна величине смещения

Для проверки справедливости предположения о том, что диффузные пики, смещенные в направлении меньших углов рассеяния из узлов с нечетной суммой индексов, являются вкладами от деформированных областей B2-фазы, были проведены модельные расчеты с помощью пакета программ DISCUS [64]. Для этого сначала моделировалась ОЦК-решетка кристалла, содержащая деформированные кластеры, т. е. пары имеющих общую грань ОЦК-ячеек, с упорядочением B2-типа, аналогично тому, как это делалось в наших исследованиях железокремнистых магнитомягких сплавов $[55,66]$. Деформация кластера задавалась смещением входящих в него атомов, как показано на рис. 7, симметрично относительно оси $\langle 100\rangle$, проходящей вертикально через центры атомов алюминия. Затем для модели „кристалла“ из большого числа атомов рассчитывалось распределе- ние интенсивности диффузного рассеяния в заданной кристаллографической плоскости.

На первом этапе недеформированные пары $B 2$-ячеек были хаотично распределены по узлам и направлениям в объеме, состоящем из $32 \times 32 \times 32=32768$ ОЦК-ячеек. После этого атомы, входящие в кластер, были смещены из идеальных позиций. Атомы алюминия раздвинуты вдоль оси пары на $0.018 \times a$, где $a$ - параметр решетки. Ближайшие атомы железа, расположенные на оси пары Al-A1, сдвигаются навстречу атому алюминия на $0.007 \times a$. Четверка атомов $\mathrm{Fe}$, находящихся на плоскости, перпендикулярной оси пары Al-Al и проходящей через середину расстояния между ними (ближайшие соседи обоих атомов Al) придвигаются к оси пары на $0.8 \%$. Другие ближайшие соседи атомов Al синхронно сдвинуты вдоль оси пары на $0.7 \%$ и на $0.5 \%$ к ней, как показано на рис. 7. Тенденции и порядок величины смещения атомов в кластере, которые использованы в данной модели, были ранее получены в первопринципных расчетах [59].

На рис. 8 приведены две картины распределения интенсивности диффузного рассеяния в плоскостях (010) и $(1 \overline{1} 0)$ для описанной выше модели локальной атомной структуры. Вблизи узлов с нечетной суммой индексов, $h+k+l=2 n+1$, где $n-$ целое число, проявляются диффузные пики, смещенные в направлении узла (000). Видно, что рассчитанное распределение адекватно описывает как экспериментально наблюдаемые в дифрактограммах от образцов сплава пики от областей с $B 2$-порядком, так и асимметрию диффузного рассеяния между основными структурными пиками в сравнении с фоном от монокристалла железа. Сканам вдоль оси $\langle 110\rangle$, приведенным на рис. 4 , соответствуют диагональ на левой картинке и ось абсцисс на правой картинке рис. 8, откуда понятно, что асимметрия фона в этих сканах обусловлена перекрытием пар диффузных пиков вблизи диагонали на левой картинке.
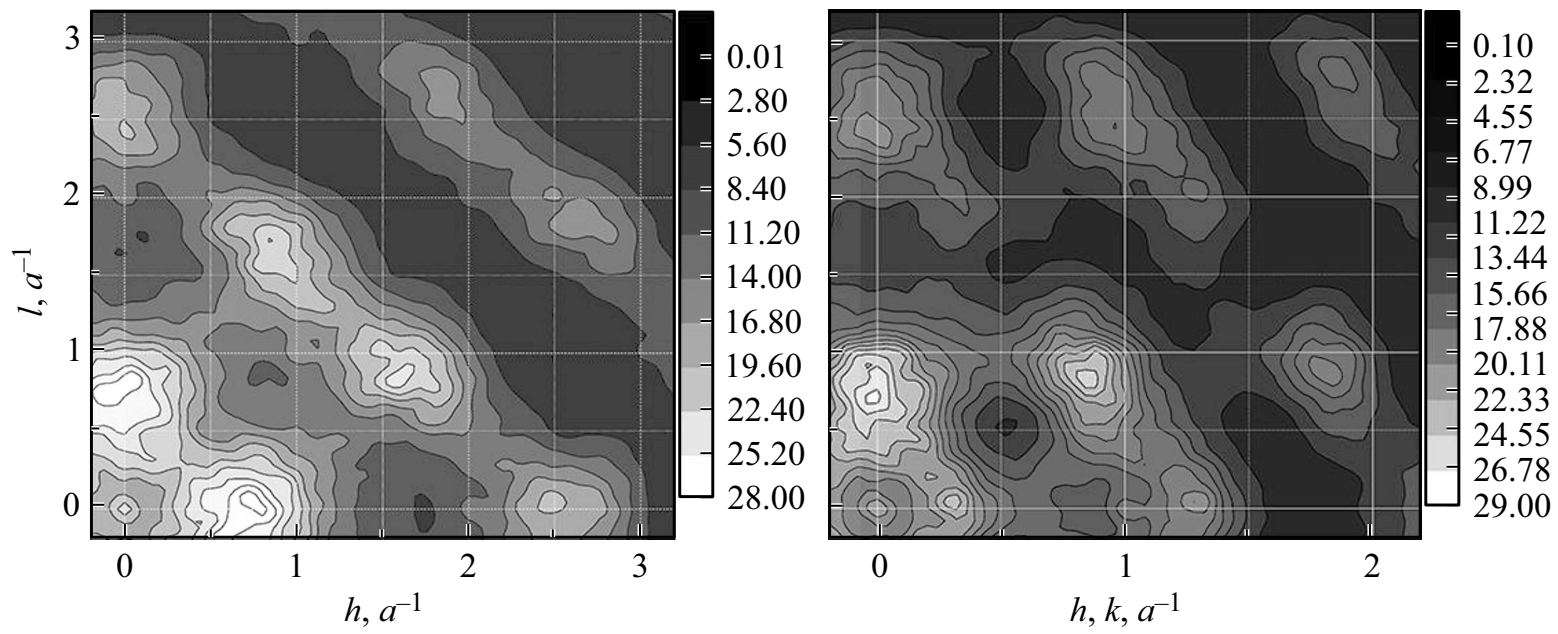

Рис. 8. Распределение интенсивности диффузного рассеяния в плоскости $(010)$ - слева и в плоскости $(1 \overline{1} 0)$ - справа. Расчет выполнен для модельной структуры с хаотичным распределением кластеров, атомы в которых смещены, как показано на рис. 7. 


\section{4. Заключение}

Проведенные рентгенодифракционные исследования атомной структуры богатых железом сплавов железоалюминий с содержанием алюминия около 7 at.\% показали, что в образцах сплава имеет место локальное упорядочение атомов. В сплаве обнаружены кластеры со средними размерами $0.6-0.7 \mathrm{~nm}$, содержащие пары атомов алюминия, являющихся между собой вторыми ближайшими соседями, что полностью соответствует предсказаниям теории [32,34], объясняющей наблюдаемую в эксперименте зависимость электросопротивления и упругих свойств богатых железом сплавов железоалюминий от концентрации и температуры. Кластер имеет структуру $B 2$-типа и состоит преимущественно из двух ОЦК-ячеек с общей гранью, в центре которых атомы алюминия. $B 2$ кластеры характеризуются осевой анизотропией формы и равновероятно ориентированы вдоль трех кристаллографических осей $\langle 100\rangle$. Ячейки в кластерах деформированы, атомы алюминия и железа сдвинуты из узлов идеальной решетки. Направление и величина смещения атомов были получены ранее в первопринципных расчетах [59]. Смещения атомов кластера являются причиной значительных сдвигов сверхструктурных пиков с нечетной суммой индексов $h, k$ и $l$ в сторону меньших углов рассеяния из их расчетного положения в $\theta-2 \theta$-сканах. Наблюдаемый в эксперименте сдвиг диффузных пиков воспроизводится в модельных расчетах.

Анизотропные и деформированные $B$ 2-кластеры сосуществуют с областями, где возникает локальное упорядочение типа $D 0_{3}$. Средний размер этих областей около $0.6 \mathrm{~nm}$, что соответствует параметру одной элементарной $D 0_{3}$-ячейки. Поскольку сдвигов диффузных $D 0_{3}$-пиков в $\theta-2 \theta$-сканах не наблюдается, можно предположить, что смещения атомов в $D 0_{3}$-кластере невелики. Следует отметить, что $D 0_{3}$-кластеры с такими характеристиками обнаружены впервые благодаря высокой чувствительности метода рентгеновской дифракции.

Исследовано влияние термообработки образцов сплава на локальное упорядочение атомов в них, в частности, отжига в парамагнитном состоянии с последующей закалкой в воду и отжига в ферромагнитном состоянии. В пределах точности измерений разницы в локальном атомном упорядочении, возникающем после таких отжигов, не наблюдается. Необходимо отметить, что не только микроструктура, но и магнитоупругие свойства образцов сплава не зависят от их термической предыстории. Это и понятно, поскольку магнитострикция (рис. 2) является структурно обусловленным эффектом.

Ранее экспериментально было показано [47], что энергия взаимодействия между атомами в сплаве железоалюминий $(19.5$ at.\% $\mathrm{Al})$ зависит от его магнитного состояния, причем эффект магнитного взаимодействия на порядок атомов наиболее значителен для взаимодействия между атомами, являющимися ближайшими соседями. Эффективное отталкивающее взаимодействие между первыми ближайшими соседями Al-Al в ферромагнитной фазе уменьшается вдвое, что резко снижает степень ближнего порядка. Поэтому возможно, что температура и выдержка в ферромагнитном состоянии были недостаточными для перехода в соответствующее равновесное состояние.

Позднее формирование ближнего порядка в $\mathrm{Fe}-\mathrm{Al}$ твердых растворах было исследовано на основе расчетов „из первых принципов“ [61]. Моделирование методом Монте-Карло ближнего порядка в сплавах Fe-Al показало, что в парамагнитном состоянии (при $T>T_{C}$ ) в сплавах с концентрацией алюминия, не превышающей 12 at.\%, имеет место неупорядоченный твердый раствор, а ближний порядок $B 2$-типа формируется в сплавах с концентрацией $15-20$ at.\% Al. Ближний порядок $D 0_{3}$-типа формируется в диапазоне концентраций $12-20$ at.\% в $\mathrm{Fe}-\mathrm{Al}$ сплавах в ферромагнитном состоянии $\left(T<T_{C}\right)$ [61]. Следовательно, и в соответствии с фазовой диаграммой (рис. 1), и в соответствии с результатами теоретического моделирования железоалюминиевые сплавы при содержании алюминия около 7 at.\% представляют собой неупорядоченный твердый раствор или A2-фазу. Тем не менее, используя высокую чувствительность метода рентгеновской дифракции удалось обнаружить небольшие области с локальным упорядочением.

В богатых железом сплавах $\mathrm{Fe}-\mathrm{Si}$ характерные для ближнего порядка типа $B 2$-пары вторых соседей атомов $\mathrm{Si}$, образующиеся в парамагнитном состоянии, сохраняются при охлаждении благодаря образованию ими устойчивого комплекса с вакансией, препятствующего их диссоциации диффузионным путем [60]. Если предположить, что в сплавах системы Fe-Al при небольших концентрациях растворенного алюминия (до 8 at.\%) действует аналогичный механизм, то для реализации локального порядка типа $\mathrm{DO}_{3}$ при отжиге в ферромагнитном состоянии необходима значительная дополнительная активация диффузионного процесса для преодоления существующего энергетического барьера в $0.3-0.5 \mathrm{eV}[60]$. Поэтому перестройка ближнего порядка $B 2$ в $D 0_{3}$ не происходит спонтанно при понижении температуры ниже точки Кюри, а развивается постепенно в процессе отжига при $T<T_{C}$, поскольку требует термической активации.

\section{Список литературы}

[1] A.J. Bradley, A.H. Jay. Proc. R. Soc. London. Ser. A 136, 210 (1932). http://dx.doi.org/10.1557/S0883769400056852

[2] A.S. Freitas, D.F. de Albuquerque, I.P. Fittipaldi, N.O. Moreno. JMMM 362, 226 (2014). doi: 10.1016/j.jmmm.2014.03.055

[3] A. Oubelkacem, I. Essaoudi, A. Ainane, F. Dujardin, J. Ricardo de Sousa, M. Saber. Physica A 389, 17, 3427 (2010). https://doi.org/10.1016/j.physa.2010.04.033

[4] R.D. Shull, H. Okamoto, P.A. Beck. Solid State Commun. 20, 9, 863 (1976). https://doi.org/10.1016/0038-1098(76)91292-8

[5] S. Takahashi, X.G. Li, A. Chiba. J. Phys.: Condens. Matter. 8, 5, 11243 (1996). https://doi.org/10.1088/0953-8984/8/50/045 
[6] S. Takahashi, H. Onodera, X.G. Li, S. Miura. J. Phys.: Condens. Matter 9, 43, 9235 (1997). DOI: 10.1088/0953-8984/9/43/009

[7] J. Steinert. Phys. Status Solidi 21, K13 (1967). DOI: $10.1002 / \mathrm{pssb} .19670210149$

[8] H. Wagner, H. Gengnagel. Phys. Status Solidi 9, 1, 45 (1965). DOI: $10.1002 /$ pssb.19650090105

[9] M. Sugihara. J. Phys. Soc. Jpn 15, 7, 1456 (1960). doi: http://dx.doi.org/10.1143/JPSJ.15.1456

[10] H.J. Birkenbeil, R.W. Cahn. J. Appl. Phys. 32, 3, 362S (1961). doi: http://dx.doi.org/10.1063/ 1.2000470

[11] H.J. Birkenbeil, R.W. Cahn. Proc. Phys. Soc. 79, 831 (1962). https://doi.org/10.1088/0370-1328/79/4/321

[12] J.B. Restorff, M. Wun-Fogle, K.B. Hathaway, A.E. Clark, T.A. Lograsso, G. Petculescu. J. Appl. Phys. 111, 3, 023905 (2012). http://dx.doi.org/10.1063/1.3674318

[13] A.E. Clark, J.B. Restorff, M. Wun-Fogle, D. Wu, T.A. Lograsso. J. Appl. Phys. 103, 07B310-1 (2008). http://dx.doi.org/10.1063/1.2831360

[14] H. Thomas. Z. Metallk. 41, 185 (1950).

[15] H. Thomas. Z. Phys. 129, 219 (1951).

[16] F. Adunka, M. Zehetbauer, L. Trieb. Phys. Status Solidi A 62 , 1, 213 (1980). doi: 10.1002/pssa.2210620124

[17] K. Oki, S. Towata, M. Tamiya, T. Eguchi. Trans. Jpn. Inst. Met. 22, 771 (1981). https://doi.org/10.2320/matertrans 1960.22.771

[18] K. Oki, H. Sagane, T. Eguchi. Jpn. J. Appl. Phys. 13, 5, 753 (1974). https://doi.org/10.1143/JJAP.13.753

[19] S.M. Allen, J.W. Cahn. Acta Met. 24, 425 (1976). https://doi.org/10.1016/0001-6160(76)90063-8

[20] S. M. Allen, J. W. Cahn. Scri. Met. 10, 5, 451 (1976). https://doi.org/10.1016/0036-9748(76)90171-X

[21] S. M. Allen. Philos. Mag. 36, 1, 181 (1977). https://doi.org/10.1080/00318087708244456

[22] W. Koster, T. Godecke. Z. Metallk. 71, 765 (1980).

[23] K. Oki, A. Yamamura, M. Hasaka, T. Eguchi. Trans. Jpn. Inst. Met. 18, 520 (1977). https://doi.org/10.2320/matertrans 1960.18 .520

[24] M. Hasaka. Trans. Jpn. Inst. Met. 21, 660 (1980). https://www.jim.or.jp/journal/e/pdf3/21/10/660.pdf

[25] H. Sagane, K. Oki, T. Eguchi. Trans. Jpn. Inst. Met. 18, 488 (1977). https://www.jim.or.jp/journal/e/pdf3/18/06/488.pdf

[26] K. Oki, A. Yamamura, K. Kudo, T. Eguchi. Trans. Jpn. Inst. Met. 20, 451 (1979). https://www.jim.or.jp/journal/e/pdf3/20/08/451.pdf

[27] K. Han, I. Ohnuma, R. Kainuma. J. Alloys Comp. 668, 97 (2016). https://doi.org/10.1016/j.jallcom.2016.01.215

[28] U.R. Kattner, B.P. Burton. Desk Handbook: Phase Diagrams for Binary Alloys, 2nd ed. Phase diagrams of binary iron alloys / Ed. H. Okamoto. ASM International, Materials Park, OH. (1993). P. 12. http://www.asminternational.org/ documents / 10192 / 1850140 / 57751G_Frontmatter.pdf/ c36eeb4e-d6ec-4804-b319-e5b0600ea65d

[29] R. Kuentzler. Ordering effects in the Fe-Al system. J. Phys. 44, 10, 1167 (1983). https://hal.archives-ouvertes.fr/jpa-00209700

[30] S.M. Allen, J.W. Cahn. Acta Met. 23, 9, 1017 (1975). https://doi.org/10.1016/0001-6160(75)90106-6

[31] G. Bertotti, F. Fiorillo. In: Magnetic Alloys for Technical Applications. Soft Magnetic Alloys, Invar and Elinvar Alloys / Ed. H.P.J. Wijn. Springer-Verlag, Berlin (1994). 7.1.2.3.3 Magnetostriction constants. pp. 55-58. https://link.springer.com/chapter/10.1007/10065028_17
[32] F. Adunka, M. Zehetbauer, L. Trieb. Phys. Status Solidi A 62, 2, 213 (1980). doi: 10.1002/pssa.2210620124

[33] H. Leamy, E.D. Gibson, F.X. Kayser. Acta Met. 15, 12, 1827 (1967). https://doi.org/10.1016/0001-6160(67)90047-8

[34] H. Leamy. Acta Met. 15, 12, 1839 (1967). https://doi.org/10.1016/0001-6160(67)90048-X

[35] L.A. Girifalco, V.G. Weizer. Phys. Rev. 114, 3, 687 (1959). doi: https://doi.org/10.1103/PhysRev.114.687

[36] В.И. Иверонова, А.А. Кацнельсон. ФММ 24, 5, 966 (1967).

[37] Н.П. Кулиш, П.В. Петренко, И.Н. Радченко. ФММ 41, 1, 125 (1976).

[38] В.И. Иверонова, А.А. Кацнельсон. ФММ 19, 5, 686 (1965).

[39] В.И. Иверонова, А.И. Минаев, В.М. Силонов. ФММ 33, 978 (1972).

[40] Е.Н. Власова. ФММ 16, 355 (1963).

[41] Е.Н. Власова, В.И. Иверонова. ФММ 15, 254 (1963).

[42] J.E. Epperson, J.E. Spruiell. J. Phys. Chem. Solids 30, 7, 1721 (1969). DOI: 10.1016/0022-3697(69)90240-6

[43] J.E. Epperson, J.E. Spruiell. J. Phys. Chem. Solids 30, 7, 1733 (1969). DOI: 10.1016/0022-3697(69)90241-8

[44] C.J. Sparks, B.S. Borie. Local Atomic Arrangements Studied by X-ray Diffraction / Ed. J.B. Cohen, J.E. Hilliard. Gordon and Breach, N.Y. Met. Soc. Conf. 36 (1966). P. 5-46. http://www . worldcat . org / title/local - atomic - arrangements studied-by-X-ray-diffraction/oclc/2073777

[45] V. Pierron-Bohnes, C. Leroux, J.P. Ambroise, A. Menelle, P. Bastie. Phys. Status Solidi 116, 2, 529 (1989). DOI: $10.1002 /$ pssa.2211160210

[46] V. Pierron-Bohnes, S. Lefebvre, M. Bessiere, A. Finel. Acta Met. Mater. 38, 12, 2701 (1990). https://doi.org/10.1016/09567151(90)90284-N

[47] V. Pierron-Bohnes, M. Cadeville, A. Finel, O. Schaerpf. J. Phys. I 1, 2, 247 (1991). https://hal.archives-ouvertes.fr/jpa-00246318

[48] B.S. Borie, C.J. Sparks. Acta Cryst. A 27, 3, 198 (1971). https://doi.org/10.1107/S0567739471000469

[49] W. Schweika, M. Monkenbusch, H. Ackermann. Physica B 156-157, 78 (1989). https://doi.org/10.1016/0921-4526(89)90592-9

[50] W. Schweika. Mater. Res. Soc. Symp. Proc. 166, 249 (1990). doi.org/10.1557/PROC-166-249

[51] M. Becker, W. Schweika. Scripta Mater. 35, 11, 1259 (1996). doi.org/10.1016/1359-6462(96)00311-9

[52] B. Schönfeld, R. Bucher, M.J. Portmann, M. Zolliker. Z. Metallkd. 97, 240 (2006). https://doi.org/10.3139/146.101248

[53] O. Kubaschewski. Phase Diagrams of Binary Fe-based Systems. Springer-Verlag, Berlin, Heidelberg (1982). 185 p. http://www.springer.com/la/book/9783662080269

[54] Yu.P. Chernenkov, V.I. Fedorov, V.A. Lukshina, B.K. Sokolov, N.V. Ershov. JMMM 254-255, 346 (2003). https://doi.org/10.1016/S0304-8853(02)00845-4

[55] Yu.P. Chernenkov, N.V. Ershov, V.A. Lukshina, V.I. Fedorov, B.K. Sokolov. Physica B: Condens. Matter. 396, 1-2, 220 (2007). DOI: 10.1016/j.physb.2007.04.008

[56] Н.В. Ершов, Н.М. Клейнерман, В.А. Лукшина, В.П. Пилюгин, В.В. Сериков. ФТТ 51, 6, 1165 (2009). DOI: $10.1134 / \mathrm{S} 1063783409060250$

[57] Н.В. Ершов, Ю.П. Черненков, В.А. Лукшина, В.И. Федоров. ФТТ 54, 9, 1813 (2012). DOI: $101134 /$ S1063783412090107 
[58] А.Р. Кузнецов, Ю.Н. Горностырев, Н.В. Ершов, В.А. Лукшина, Ю.П. Черненков, В.И. Федоров. ФТТ 49, 12, 2184 (2007). DOI: $10.1134 / \mathrm{S} 1063783407120128$

[59] М.В. Петрик, Ю.Н. Горностырев. ФММ 114, 6, 514 (2013). DOI: 10.1134/S0031918X13060112

[60] О.И. Горбатов, А.Р. Кузнецов, Ю.Н. Горностырев, А.В. Рубан, Н.В. Ершов, В.А. Лукшина, Ю.П. Черненков, В.И. Федоров. ЖЭТФ 139, 5, 969 (2011). DOI: $10.1134 / \mathrm{S} 1063776111040066$

[61] O.I. Gorbatov, Yu.N. Gornostyrev, A.R. Kuznetsov, A.V. Ruban. Solid State Phenomena 172-174, 618 (2011). DOI: $10.4028 /$ www.scientific.net/SSP.172-174.618

[62] Ю.П. Черненков, В.И. Федоров, В.А. Лукшина, Б.К. Соколов, Н.В. Ершов. ФММ 100, 3, 39 (2005). http://impo.imp.uran.ru/fmm/Electron/vol100_3/abstract6.html

[63] G. Bertotti, F. Fiorillo. In: Magnetic Alloys for Technical Applications. Soft Magnetic Alloys, Invar and Elinvar Alloys / Ed. H.P.J. Wijn. Springer-Verlag, Berlin (1994). 7.1.2.2.1 Phase diagrams, lattice parameters and density, thermal expansion. P. 35-44. https://link.springer.com/chapter/10.1007/10065028_17

[64] Th. Proffen, R.B. Neder. J. Appl. Crystallogr. 30, 171 (1997). DOI: $10.1107 / \mathrm{S} 002188989600934 \mathrm{X}$

[65] A.L. Patterson. Phys. Rev. B 56, 10, 978 (1939). DOI: https://doi.org/10.1103/PhysRev.56.978

[66] Н.В. Ершов, Ю.П. Черненков, В.А. Лукшина, В.И. Федоров. ФТТ 51, 3, 417 (2009).

DOI: $10.1134 / \mathrm{S} 1063783409030019$

Редактор Т.Н. Василевская 